\title{
ETNOLOGIA E FENOMENOLOGIA. UM COMENTÁRIO DAS OBRAS DE MARCELO BÓRMIDA, TIM INGOLD E EDUARDO VIVEIROS DE CASTRO*
}

Seguramente todos conhecem, em maior ou menor medida, a obra de Eduardo Viveiros de Castro e a de Tim Ingold. Seguramente, também, poucos conhecem a obra do antropólogo ítalo-argentino Marcelo Bórmida (I925-I978), porque, neste caso, corresponde a falar de uma "não-tradição", termo que Andre Gingrich (2005: 62) usou para se referir à antropologia da língua alemã, e que, acredito, cai-lhe muito bem, já que sua antropologia se baseava na denominada Escola Histórico-Cultural (EHC), de origem germânica, formando, assim, parte de uma esquecida linha de trabalho que teve grande continuidade no passado, mas que hoje carece de uma positiva representação no mundo acadêmico.

Bórmida é possivelmente uma das figuras mais polêmicas da antropologia argentina. O seu perfil foi resgatado pela primeira geração de antropólogos formados na Universidade Nacional de Buenos Aires (UBA), todos eles extremamente críticos do seu pensamento e trajetória política, mas encantados com sua erudição e inteligência (Bartolomé, I982: 7; Guber \& Visacovsky, 2006). Nascido em Roma, Bórmida estudou ciências biológicas na universidade homônima e trabalhou com o raciólogo Sergio Sergi até I946, quando se estabeleceu na Argentina. Continuou seus estudos na UBA onde obteve os títulos de professor, licenciado e doutor quase simultaneamente e sob a orientação de José Imbelloni (I885-I967), antropólogo ítalo-argentino associado ao fascismo e ao peronismo. A capacidade de Bórmida para continuar com suas pesquisas e cargos na academia argentina apesar do convulsionado contexto político 
da segunda metade do século XX é uma de suas principais qualidades (Boschín, I99I-I992: I29; Guber \& Visakovsky, I999), ocupando o lugar central na antropologia argentina entre 1956 e I978 (independentemente de os governos serem democráticos de facto ou não), e sua influência continuou até vários anos depois de sua morte.

Sobre a sua obra, se em um primeiro momento, que poderíamos situar em I948, com a publicação de algumas resenhas, seus trabalhos são de clara e aberta adesão à EHC - na linha considerada Antropologia, orientada para o estudo da relação existente entre raça e cultura -, depois de 1956 vão paulatinamente voltando-se para uma posição que denomina Etnologia, e que enfatiza o conceito de cultura. Porém, em um terceiro momento, no final da década de I960, sua posição começa a ser abertamente fenomenológica. Embora se saiba que as influências fenomenológicas foram comuns na antropologia e na sociologia anglo-saxã da época, a abordagem de Bórmida parece ser totalmente independente dessas linhas de investigação e encontra-se mais próxima do desenvolvimento das etnologias germânica e italiana.

Neste artigo, centrado em minhas investigações a respeito do desenvolvimento da antropologia na Argentina, vou analisar dois dos primeiros trabalhos de Bórmida abertamente etnológicos e fenomenológicos para, assim, explorar certas relações a partir da etnologia, com a obra de Viveiros de Castro e, da fenomenologia, com as posições de Ingold. Para isso também serei obrigado a ampliar o campo de análise para outros antropólogos argentinos vinculados a Bórmida, além de outros antropólogos e cientistas sociais do campo acadêmico anglo-saxão e francês. O sentido da comparação é tentar encontrar similitudes e diferenças, mas também ver até que ponto diversas questões de autores como Viveiros de Castro ou Ingold estão ancoradas também em "resíduos de não-tradições".

\section{O ANTISSOCIOLOGISMO E A APROXIMAÇÃO AO PÓS-SOCIAL}

No volume XII da revista Runa, editada pela Faculdade de Filosofia e Letras da Universidade de Buenos Aires apareceram os três artigos com as primeiras abordagens de Bórmida tentando desenvolver uma etnologia tautegórica. ${ }^{\mathrm{I}}$ Para este autor, a etnologia é o estudo dos povos bárbaros, ou seja, do não-ocidental; e no caso do mundo indígena americano considerará que o locus central do seu pensamento e ação se encontra nas suas mitologias. Estas seriam de uma qualidade diferente dos relatos ocidentais, pois nas narrativas míticas "conceitos como 'super-humano', 'humano', 'maravilhoso', 'extra-humano' e inclusive 'histórico', embora tenham um sentido bastante preciso na linguagem e na conceituação do Ocidente, não têm necessariamente o mesmo significado nas outras culturas, que são justamente aquelas de onde se originam, direta ou indiretamente, o mito, a fábula, o conto e a lenda" (Bórmida, I969-I970a: Io). 
Por isso, uma primeira crítica poderia ser dirigida a Bórmida tendo em vista o fato, assinalado por Ingold, de que, enquanto as culturas não-ocidentais estão sempre em algum lugar (neste caso, os indígenas americanos), o Ocidente está simultaneamente "em nenhum lugar" ou "em todas as partes" (Ingold I993: 2 I4). Os bárbaros de Bórmida estão claramente localizados; o mundo e o pensamento ocidental, não. Assim, o princípio que rege seu pensamento não será a igualdade, mas a diferença. Será claramente uma antropologia que desenvolverá "a arte das distâncias" (Viveiros de Castro, 20I0: I7).

Bórmida aceitava a existência de uma lógica interna do mito, porém, não da mesma maneira que se poderia apresentar em obras diferentes, mas tradicionalmente aceitas, da disciplina. Para Bórmida, assim como para seu mentor Imbelloni, e diferentemente de certos autores que hoje consideramos fundadores da antropologia e das ciências sociais em geral, como Durkheim, a etnologia não deve se distanciar totalmente da filosofia, mas beber dela Essa influência da filosofia, entretanto, não implica "nem uma filosofia com gente dentro", como apontou Ingold, nem necessariamente tomar conceitos e práticas indígenas para fazer uma filosofia própria, como considerará Viveiros de Castro (20I0: 20I). O jogo de Bórmida é então contrário ao de Viveiros de Castro: não se faria uso do pensamento indígena para ampliar o mundo ocidental, mas se utilizaria dos conceitos da filosofia ocidental para entender o mundo indígena.

Tanto para Bórmida como para Imbelloni, há dois filósofos europeus fundamentais: um é Giambattista Vico (I668-I744), que, entre outras coisas, é considerado o primeiro a afirmar "que os contos populares procedem de culturas muito remotas no tempo e guardam relação com a organização social, jurídica e com a ética daquelas" (Bórmida, I969-I970a: Io), assim como o responsável por ter cunhado um conceito muito caro ao difusionismo alemão: o da degeneração das culturas. O outro filósofo fundamental será Friedrich Wilhelm Joseph von Schelling (I775-I874) a quem Bórmida atribui ter fixado "a ideia de uma lógica interna dos relatos míticos [e] que a compreensão do mito começa quando se reconhece que não se trata de um mundo de imagens caprichosas, mas de um mundo que possui uma peculiar necessidade (isto é, que se remete a certos princípios básicos) e ao qual, em consequência, lhe corresponde certa realidade" (Bórmida, I969-I970a:Io). Mas "essa lógica" é diferente da que, por exemplo, poderia utilizar alguém com quem Bórmida vai discutir diretamente, como Bronislaw Malinowski, que apontava uma conexão íntima entre "de um lado a palavra, o mythos, os contos sagrados de uma tribo e, de outro, seus atos rituais, ações morais, organização social e inclusive atividades práticas" (Malinowski, I985 [1926]: I07); e simultaneamente diferenciava o mito (emotivo e intencionado) da História (como estudo desapaixonado do passado). Por isso, para Malinowski não há nada de real no primeiro, já que não serve como explicação de como a natureza funciona, nem como explica- 
ção "desapaixonada" de como a história do grupo em questão se desenvolveu. Assim, verificam-se duas grandes diferenças entre a concepção de Malinowski e a de Bórmida. Uma delas é que, para o primeiro, o mito é um fato moral e só se compreende no seu contexto imediato, o da organização social "aqui e agora"; o mito é um relato que seria manipulado para criar coesão no grupo, mesmo em situações conflituosas. Afinal, é apenas uma construção social. De fato, na opinião de Malinowski, o mito aparece onde há conflito, não para acentuá-lo, e, sim, para tentar repará-lo; nesse caso, o autor antecede Edmund Leach, para quem o fato de contar uma história tem como propósito validar o status de um indivíduo e, por isso, denegrir o de outro (Leach, I995 [I954]: 309). Malinowski (com sua ênfase no equilíbrio) e Leach (com sua ênfase nos constantes desajustes entre a estrutura social, a cultura e os interesses dos indivíduos) iniciam um tipo de pesquisa que assume o caráter político como central no mito. Uma narrativa que, por um lado, faz referência ao passado, a seres sobre-humanos, transformações, erros etc., mas que na realidade trataria do presente e tentaria solucionar ou manipular lutas políticas e questões de poder no interior dos grupos.

As contribuições que essa nova posição sociológica deu à antropologia são inegáveis. Mas Bórmida decide explorar outro viés. Não quer explicar o fenômeno do mito recorrendo a outro fenômeno; não quer subsumir o mito à política, à economia ou ao social. O fato de o mito fazer referência e ser manipulado para justificar ou disputar uma luta política atual é um tema menor que não chega a explicar nem o mito, nem o comportamento indígena na sua totalidade. Para Malinowski, o mito não é mais do que um reflexo da organização social e só é compreensível no seu contexto social, posição que poderíamos denominar sociologismo. O dado, o real, o objetivo, encontra-se na organização social que o antropólogo pode chegar a descrever, e não nos mitos que os nativos podem chegar a contar. Assim, para Malinowski o mito "não diz nada que já não diga a mesma vida social" (Vernant, I99I: 203). Para Bórmida, ao contrário, o mito encontra-se no que o relato tem de geral, pois aí está o caráter necessário e real do mito. ${ }^{2}$ Considero essa crítica ao sociologismo um dos aspectos que trazem Bórmida ao debate atual, e que o aproximam de antropólogos contemporâneos como Viveiros de Castro ou Ingold: uma desconfiança de que toda esfera humana que não conhecemos (a religião, os mitos, as "irracionalidades") seria traduzível para o que é suposto que conhecemos (a política, a economia ou "o social"). Contudo, a similitude também termina aí, porque nem para Viveiros de Castro, nem para Ingold haveria uma sociedade ou cultura como coisa aí fora. Porém, Bórmida considerou a cultura como algo que as pessoas ou os grupos portam. De qualquer maneira, não deixa de ser uma posição que foge do determinismo social. 


\section{O MITO: VERDADE VIVIDA}

O Bórmida da década de ig6o estabelecerá que "todo relato mítico é original desde que improvisado no momento seguindo o guia de um esquema genérico, o qual o narrador enriquece com os detalhes que constituem sempre uma criação individual" (1969-I97ob: 58). Denominará isso consciência mítica. Aceita que o mito implica certos postulados morais, mas isso não é o essencial nele, pois “a exemplaridade não [é] uma característica necessária do mito e [não afeta] seu caráter essencial de verdadeiro" (Bórmida, I969-I970a: I5). O importante é que para o nativo o mito é verdade.

Bórmida parece aceitar que, do ponto de vista da consciência mítica, o mundo não está dividido entre humanos e não humanos, e dirá que devemos levar ao limite essa concepção do mundo, analisá-la nos seus próprios termos e não traduzi-la para a linguagem ocidental:

Todo ritual aparece sob uma luz de coerência se partimos dos supostos que guiam a ação do caçador hiperbóreo: que a foca pensa e fala como o homem, que sobrevive à sua morte e se reencarna, que guarda com respeito ao homem uma relação de boa vontade e colaboração e que, no fundo do mar, existe uma velha monstruosa de quem os animais marinhos obedecem às ordens. Dito em termos gerais: que o mundo é uma estrutura social que inclui, em uma relação constante, homens, animais e deuses. Toda vez que partimos dessa ideia básica, um sem-número de atitudes e seres, à primeira vista arbitrários e fantásticos, nos serão mostrados sob uma luz de coerência e adquirirão uma realidade particular e um sentido particular (Bórmida, 1969-1970a: 26).

O antropólogo ilustrado entenderá que "do ponto de vista do nativo" a foca pensa como o humano e no fundo do mar existe uma velha monstruosa da qual os animais marinhos obedecem às ordens. Mas, em seguida, esclarecerá que esses caçadores hiperbóreos "refletem" ou "representam" nos animais a "natureza objetiva" da sua organização social e fará coisa semelhante com os "seres sobrenaturais" como a velha que vive no fundo do mar. Em suma, nas palavras de Bórmida, eles tomam o mito como uma alegoria, mas como uma alegoria da qual nem o próprio indígena é consciente. O único consciente é o antropólogo. Agora, o que resta do fato de que para o indígena aquilo que conta, e nos conta, é concebido como real? Nesse conjunto de ideias de Bórmida é evidente que a sociabilidade, a associação, não existe só entre seres humanos. Para o indígena a "estrutura social" vai além do que nós consideramos "humanos" e inclui, nesse caso, a foca e a velha monstruosa que habita o fundo do mar. Para o indígena isso não é uma fantasia do tipo que poderíamos ver em um filme infantil da Disney - no qual, de forma alegórica, os animais têm características humanas -, mas é a própria realidade e a explicação do seu mundo.

Para Bórmida, esse não é só um problema do funcionalismo malinowskiano, mas também do estruturalismo: 
As "estruturas conscientes" de Lévi-Strauss referem-se somente ao aspecto externo, "morfológico" dos fatos culturais mutilados da sua face vivencial, isto é, separados do contexto de ação e de emotividade que constitui seu aspecto mais essencial [...]. Um sistema de parentesco não é somente um conjunto de relações, uma estrutura que pode ser representada elegantemente por meio de esquemas gráficos, mas o patrimônio de ideias, crenças e vivências que tornam possível e dão sentido a essas crenças [e] de maneira alguma a reciprocidade, embora explique certo nível das relações de parentesco, é suficiente para explicar o horror sagrado perante o incesto (Bórmida, 1969-1970a: 37).

O mito, então, não é apenas um relato que se refere a como é ou deveria ser a organização social, mas um relato que emociona; e essa emoção não é uma coisa a mais para acentuar a norma, porém, na visão de Bórmida, teria uma validade em si mesma. Essa emoção não corresponde à estrutura, mas ao mundo vivido, e não subjaz a nada, mas é evidente em si mesma. Estes são dois pontos centrais da fenomenologia. Por essa razão, o que o mito afirma merece ser estudado em si mesmo.

Ironicamente, a análise da "estrutura", tanto na sua acepção funcionalista quanto na estruturalista é, para Bórmida, uma análise subjetiva da cultura indígena:

Um etnógrafo pode muito facilmente descrever uma cultura partindo da economia ou da organização social e considerar todos os seus outros aspectos em função dessas categorias [...]; desde já essas formas de reducionismo são legítimas e úteis para outros fins. O erro consiste em considerá-las como a única e verdadeira forma de descrever a cultura de um modo objetivo, quando na realidade trata-se de uma interpretação subjetiva da mesma (1969-1970a: 44).

Um dos principais críticos da fenomenologia de Bórmida é Carlos Reynoso, para quem a fenomenologia em geral, e a de Bórmida em especial, é somente um tipo de aproximação emic (2006: 207). Porém, devemos levar em conta que aquilo que é habitualmente considerado distinção emic-tic é simultaneamente uma distinção hierarquizada de um suposto subjetivo-objetivo, em que a visão do nativo é subjetiva e a do pesquisador objetiva. Porém, deve ser ressaltado que Bórmida, nesse caso, está dizendo exatamente o contrário, e a interpretação subjetiva seria a do pesquisador que coloca no plano do objetivo o que ele concebe previamente ser real, e no plano da subjetividade aquilo que considera fantasia indígena. Isso ocorre porque para as teorias ortodoxas da cultura na antropologia a percepção que os nativos têm a respeito do mundo é sempre "indireta": quem percebe não pode acessar o mundo diretamente, mas tem que descobri-lo, ou construi-lo, a partir da matéria-prima registrada através dos sentidos (Ingold, I993: 219).

No caso indígena, Bórmida dirá que essa unidade entre humanos e não-humanos com vontade já está marcada pelos mitos de origem: no princípio - e à diferença das mitologias, filosofias e ciência ocidentais - todos eram humanos (Bórmida, I969-I970a: 30). Essa seria a base do pensamento 
americano. É interessante observar que Eduardo Viveiros de Castro afirma algo semelhante quando diz que no mito ameríndio "a condição comum aos homens e aos animais não é a animalidade, mas a humanidade" (Viveiros de Castro, 20I0: 50). Primeiro foi a humanidade, e posteriormente, por causa de uma série de transformações, o mundo passou do humano ao animal, ao vegetal e ao mineral. A rigor, para Bórmida, nem os mitos falam do passado, uma vez que "o homem pode se introduzir nele a qualquer momento" (I969I970a: 23), nem assinalam que tudo foi humanidade no princípio, já que nas mitologias há sempre um resto do qual não se fala e que corresponderia ao que estava antes do começo (Bórmida, I969-I970a: 30). Também não se encontra uma ideia clara da humanidade no pensamento americano, pois, como observa o autor, existe em muitos casos um mito para explicar a origem do homem e outro para explicar a origem da mulher, e ao mesmo tempo mitos de origem diferente para distintos grupos humanos. Por isso, identifica na consciência mítica uma "carência de um sentido unitário do humano" (Bórmida, I969-I970b: 59); o que posteriormente Viveiros de Castro (2010: 27) definiria como "uma das manifestações típicas da natureza humana, a negação da sua própria generalidade".

\section{REPRESENTAÇÃO OU PRESENÇA}

Para Bórmida, o conto e a lenda podem ser degenerações dos mitos, mas simultaneamente uma narração profana não é necessariamente degeneração, porque pode ser transformada em um mito, se mudar sua função. Por isso, não há, especificamente falando, nem evolução, nem degeneração. Para este autor, a tradição não é cumulativa, pois, como é oral, "vai se perdendo à medida que vão aparecendo dados mais novos" (Bórmida, I969-1970a:I7). Porém, essa contínua atualização não acarretaria mudanças. Por outro lado, as personagens míticas, seus heróis, têm a característica da atemporalidade, e seriam, segundo Bórmida, diferentes dos heróis bíblicos ou da antiguidade clássica europeia (Bórmida, I969-I970a: I9). Seria esse um tempo do tipo circular em vez de linear. Observa-se, então, uma semelhança entre o pensamento de Bórmida e as Escolas simbolistas, desenvolvidas em autores como Creuzer, Schelling ou Eliade, que opõem o símbolo ao signo. Este último seria arbitrário na sua relação com o que significa, faz referência a uma relação exterior a ele, à que remete como objeto de conhecimento (referente). Por outro lado, o símbolo acarreta um aspecto natural e concreto; está vinculado em parte ao que expressa. Por isso o símbolo mítico pode ser considerado tautegórico, não representa outra coisa, porém se apresenta e se afirma a si mesmo (Vernant, I99I: 200).

Agora, qual é a diferença radical a que se refere Bórmida? No final das contas, uma grande parte de nossas narrativas (escritas, visuais etc.) faz refe- 
rência a espíritos, fantasmas, vida além da morte e outra grande quantidade de fenômenos que consideramos "sobrenaturais" e que, embora no discurso científico não sejam aceitos como reais, do ponto de vista do senso comum, ao menos têm a dúvida acerca da sua existência admitida. Na perspectiva de Bórmida, para o indígena não existem milagres (I969-I970a: 3I). Se o Ocidente em algum momento criou uma distinção entre aquilo que pertence a uma natureza exterior ao humano - e, em consequência, "mais objetiva", "mais real" - e o separou daquilo que pertence à subjetividade dos seres humanos, separando assim o objetivo e o subjetivo, o natural e o cultural, a realidade e a fantasia, para uma grande parte da humanidade (entre eles os indígenas americanos) essa dicotomia não existiria. Eis, na sua concepção, a grande ruptura entre o pensamento ocidental e o pensamento mítico; que conduz ao erro conceitual de querer analisar um relato que é, "do ponto de vista nativo", real, como se fosse uma fantasia ou um "reflexo" de algo mais real e objetivo que só o antropólogo pode acessar.

É claro que isso já foi analisado pela Escola Sociológica Francesa e pelo estrutural-funcionalismo britânico. Mas justamente para autores como James Frazer, o pensamento primitivo é lógico, porém errado (Frazer, I996 [I922]: 75). Evans-Pritchard (I976 [1937]), por sua vez, aceita que o Azande acredite efetivamente na bruxaria, mas em certo sentido o Azande não perceberia que, quando se refere às forças da bruxaria, está na realidade se referindo, no sentido durkhemiano, às forças morais e sociais do seu grupo. Também para Frazer:

\begin{abstract}
O selvagem concebe com dificuldade a distinção entre o natural e o sobrenatural, comumente aceita pelos povos já mais avançados. Para ele, o mundo está funcionando em grande parte dominado por certos agentes sobrenaturais que são seres pessoais que atuam por impulsos e motivos semelhantes aos seus próprios, e como ele, propensos a modificá-los por apelações à sua piedade, aos seus desejos e temores. Em um mundo assim concebido não vê limitações ao seu poder de influir sobre o curso dos acontecimentos em benefício próprio (Frazer, 1996 [1922]: 33).
\end{abstract}

Algo semelhante era apontado por Durkeim e Mauss: "se descemos até às sociedade menos evoluídas que conhecemos, as que os alemães denominam, com um termo um pouco vago, Naturvölker, tropeçamos com uma confusão mental ainda mais absoluta. Aqui, o indivíduo mesmo perde sua personalidade. Entre ele e o exterior, entre ele e seu totem, a distinção é completa" (Durkeim \& Mauss, I97 I [1903]: I5). Pode-se ver como, para o pensamento da época em que Durkheim escrevia, a escola alemã tinha grande prestígio. Por outro lado, e à diferença de Bórmida, Frazer não vê uma ruptura radical entre o pensamento científico e a magia: "a magia rudimentar é o princípio da ideia moderna de Lei Natural” (Frazer, I996[I922]: 33). Esse saber, diferentemente do científico, é um saber meramente prático e utilitário: “O mágico primitivo conhece somente a magia em seu aspecto prático; nunca 
analisa os processos mentais nos quais sua prática está baseada e nunca os reflete sobre os princípios abstratos entranhados nas suas ações [...] para ele a magia é sempre uma arte, nunca uma ciência" (Frazer, I996[1922]: 34).3 Apesar das visões pejorativas sobre o humano não-ocidental dos pensadores europeus e da influência que suas ideias tiveram sobre o colonialismo ocidental, continuamos considerando-os "clássicos" e fazendo malabarismos para salvar suas maneiras de pensar. Não costumamos ser tão tolerantes com nossas próprias tradições. No caso de Bórmida, o saber contido no mito permite ao selvagem atuar no mundo no qual vive. Não é uma crença, mas uma experiência, e a rigor não é um obstáculo, mas algo produtivo. Por isso, voltando à ideia originária de Schelling, o mito precisa de uma compreensão tautegórica, não alegórica. Se seguirmos nesse último caminho, o da alegoria, estaremos procurando algo racional que se considera como essencial (como um fenômeno natural, uma relação de parentesco, um cisma político, uma prática econômica ou uma operação mental) da forma mítica, compreendida como uma mera fantasia. Mas, para Bórmida, é preciso "procurar como também a forma é apresentada como racional e, portanto, como essencial e necessária" (Bórmida, I969-I970a: I2). O mito não é, então, uma fantasia com uma essência real que o nativo, no fim das contas, não conhece; ele é real em si mesmo, no fundo e na forma. Mas é real só se o consideramos não dentro do contexto social do qual é parte, mas do mundo mental e vivido ao qual pertence. Assim, a partir da fenomenologia, o autor retoma um velho problema da Escola Histórico-Cultural, que é a análise da forma.

É claro que a Escola Histórico-Cultural propõe uma teoria das formas. Na antropologia física, ela está preocupada com as formas dos crânios e, em menor medida, com a somatologia; na arqueologia, está preocupada em tipificar a forma dos objetos materiais e as técnicas utilizadas para sua construção; na etnologia e no folclore, com as formas dos rituais, as danças etc. Para Fritz Gräbener (I940 [I9II]: 40), um dos primeiros e principais sistematizadores dessa escola, "a existência de cada uma das técnicas está unida à existência de determinadas formas de cultura". É no critério da forma (e, dentro deste, na ornamentação e no estilo) que, segundo esta Escola, serão apontadas as normas, não só para a determinação do lugar, mas da pureza da cultura, algo muito importante para a EHC. Contudo, forma para a Escola não é exatamente o mesmo que forma tal como entendida nesta última fase de Bórmida. Para a EHC, o real está no objeto ou no modo como o relato foi compilado. Na forma está a realidade, mas somente na medida em que nos permite distinguir uma cultura de outras de maneira externa (objetiva), ou seja, em relação a como cada cultura concebe a si própria. No entanto, nada de real há no caso concreto do mito; a única ressalva para que haja algo de verdade é que, como nos trabalhos da primeira fase de Bórmida sobre a história da Ilha de Páscoa, em vez de mitos, as narrativas sejam tradições históricas, ou seja, que tenham 
um formato semelhante, mas inferior à História ocidental (ver Bórmida, I95I). Neste sentido, a EHC assemelha-se à tradição de pensamento antropológico anglo-saxão e francês: no melhor dos casos, o pensamento primitivo pode ser logicamente coerente, mas é sempre errado em relação à ciência ocidental, ou seja, quanto ao seu saber sobre como a natureza (e a própria vida social) realmente é. Por isso, finalmente, e no melhor dos casos, com a boa intenção do homem branco de salvar o nativo, o mito é analisado como alegoria ou como representação: em si mesmo não diz nada, é só fantasia, no máximo, de valor estético. Filtrado pelo especialista, porém, permite distinguir uma cultura de outra (no caso da EHC), ser uma reflexão sobre a estrutura social ou certos conflitos políticos ou econômicos do grupo de onde a narrativa foi tomada (tal qual é concebido pelo funcionalismo e o estrutural-funcionalismo britânico), ou referir-se a uma operação mental formal para além do seu conteúdo (tal qual é desenvolvida pelo estruturalismo de Lévi-Strauss). O mito contado é concebido como real; isso implica que a concepção total do mundo daquele que o conta, sua ontologia e sua epistemologia, seja substancialmente diferente da do antropólogo? O que aconteceria se o mito saísse da razão e da lógica? Se vamos por este caminho, o mito não representa nada, não é metáfora, nem alegoria. É real, tautegórico, e implica uma presença: “a representação dramático-ritual de um relato mítico se confunde, em nível etnográfico, com os acontecimentos que representa, se fazendo, em certa medida, contemporâneo daqueles" (Bórmida, I969-I970a: I3). A Escola Sociológica Francesa e o estrutural-funcionalismo distinguem entre um mundo real e objetivo (que é o do pesquisador) e um mundo construído e subjetivo (que é o do nativo). A fenomenologia de Bórmida não assume isso, tampouco concorda que uma correta tradução do mito seja dar-lhe uma lógica semelhante à ocidental (exterior, como em Malinowski, ou inconsciente, como em Lévi-Strauss).

O mito não é lógico nem de fundo, nem de forma, e é utilizado pelo primitivo para explicar como a realidade é. Parece então que para o nativo, à diferença do pensamento ocidental, o mundo não é coerente, e este fato não seria um problema, ou pelo menos um obstáculo, para nele se viver e dele ser parte: "em um mundo regido por vontades e intenções, com frequência caprichosas e imprevisíveis, a explicação da interferência arbitrária tem plena vigência pois, no caso do fracasso, prestar-se-ia atenção, não às variáveis constantes, mas às variáveis variáveis que o determinaram" (Bórmida, I969I970a: 25). Por isso, em termos metodológicos, "a tradução de um texto mítico resolve-se em uma hermenêutica do mito através do esclarecimento de seu sentido" (Bórmida, I969-I970b: 62). Os seres e ações dos que falam não representam, mas mostram sua presença. A rigor, essa ideia não tem nada de novo, nem de original, e só para citar um mentor do próprio Bórmida, lembremos as ideias de Oswald Menghin, que dizia que "o homem primitivo acredita em uma identidade mística entre o objeto e sua imagem e, consequentemente, 
que também acontece com o original tudo o que ocorre com a imagem" (Menghin, I952: I9). Portanto, o objeto (o real) e sua imagem (a representação) são a mesma coisa. Para Bórmida, toda teoria (o mito) implica uma prática (o rito):

A concretude mais imediata desta ontologia existencial é o rito, no qual conhecimento-de-mundo e ação-no-mundo se confundem em algo que bem pode ser considerado como um saber pragmático no qual a referência mítica proporciona, ao mesmo tempo, o conhecimento de realidade e as normas para atuar perante ela. Daí que mito e rito constituem quase sempre uma unidade inseparável, pois o primeiro é um conhecimento através de uma ação e o segundo é uma ação que tem sentido somente com referência a esse conhecimento atuado (Bórmida, 19691970a: 21).

No Ocidente, a partir da interpretação que a Europa fez do pensamento grego antigo, "o mito define-se pelo que não é, uma dupla oposição ao real, por um lado (o mito é ficção), e ao racional, por outro (o mito é um absurdo)" (Vernant, I99ı: I70). Na mesma linha, Ingold atribui a Bacon a distinção entre o mundo "em si" da realidade única que está na natureza (e só pode ser descoberta pela investigação científica) e os vários mundos imaginários que as pessoas de diferentes épocas e lugares invocam (mundo produto da ignorância dessas pessoas em relação à ciência e seus métodos), assumindo essas fantasias como realidade (Ingold, 20I2: I6). Assim, o imaginário é irreal, ou seja, aquilo que não existe 4 (Ingold, 20I2: I7). Bórmida também realiza uma distinção radical entre o pensamento ocidental e o dos bárbaros. Contudo, afasta-se do pressuposto comum de que o pensamento do antropólogo seria um saber real e o do nativo, subjetivo, pois cada um dos saberes implica uma metafísica:

O esquimó atua não somente sobre a base de uma crença, mas também de uma experiência que a confirma [...]. Por experiência a ciência moderna entende a verificação de algum fato; essa verificação se afirma em procedimentos baseados em certas ideias que a regem, mas que não são inatas ao homem e, sim, vão se afirmando ao longo do devir do saber ocidental. Todo o sistema demonstrativo da ciência tem valor e sentido apenas dentro de uma forma de conceber a realidade, previamente definida de uma maneira implícita ou explícita, que é a que enunciaram e fizeram conscientes os fundadores da ciência moderna. Na consciência mítica também existe a verificação da eficácia de uma ação e os casos em que a experiência se manifesta negativa, segundo os princípios da ciência ocidental, podem ser explicados sobre a base de outras ideias essenciais que integram uma concepção de mundo diferente da que fundamenta essa ciência (Bórmida, 1969-1970a: 24).

Vimos mais acima quais são esses pressupostos: a ciência pressupõe uma natureza homogênea e previsível; a consciência mítica pressupõe um mundo heterogêneo e não previsível. Mas os dois mundos seriam eficazes. Encontramo-nos, assim, frente a um construtivismo radical, segundo o qual aquilo que "o antropólogo chama cosmologia é, para as pessoas estudadas, um mundo de vida” (Ingold, 2002: I4). 
O bárbaro, por sua vez, está relacionado a um tipo de pensamento que é irracional, no sentido de alheio à razão, e que Bórmida denominará consciência mítica:

Um conjunto de formas de pensamento e de ação que permite e dá sentido a determinadas atuações e seres, tanto no mito como na vida de uma cultura [...] como um todo integrado de estruturas de consciência que constituem a racionalidade interna de um modo de ser e de atuar, que não teria nenhuma coerência a partir de uma concepção do mundo tal como nos é proporcionada pelo saber ocidental e pelas normas pragmáticas que deste são derivadas [...]. Evitar o equívoco - tanto mais grave se é inicial - de conceber a consciência mítica como uma ciência mítica do mundo, vale dizer como um conhecimento da realidade que seria diferenciado do da ciência ocidental apenas por partir de premissas diferentes perante uma mesma situação (Bórmida, 1969-1970a: 23).

A explicação mítica, portanto, não é um teorizar desinteressado, mas uma forma de se relacionar com o mundo, uma forma de se estar com ele.

\section{ETNOLOGIA E PERSPECTIVISMO}

O caminho subia e descia:

"sobe ou desce da maneira que vai ou vem. Para quem vai, sobe; para quem vem, desce". Juan Rulfo, Pedro Páramo, I955.

Como o mundo do bárbaro e do ocidental são, em princípio, substancialmente diferentes, o contato entre um e outro costuma ter características catastróficas:

Daí que o contato com a civilização ocidental faça surgir nos povos etnográficos problemas que oferecem matizes da tragédia. Confrontada sua verdade-para-a-ação a outra verdade que a vence e lhe priva da segurança que lhe brindava a sua, impossibilitado de assumir racionalmente essa nova verdade que lhe resulta incompreensível, ficam presos em uma contradição insolúvel de um mundo-para-a-ação que entendem e que demonstra sua falsidade em seu fracasso e outro mundo - o dos brancos, sempre exitosos - que manifesta uma eficácia ininteligível e, portanto, não manejável. Daí a mimese incoerente desse estar-no-mundo triunfante, os sincretismos arbitrários, a assunção esporádica de traços isolados, desintegrados do fundamento de racionalidade e dos supostos que são sua razão de ser, o inevitável fracasso e a miséria cultural sem esperanças (Bórmida, 1969-1970a: 27).

No entanto, o que ocorre depois do contato? Para a EHC, havia uma constante tensão entre encontrar tipos puros, sua mistura com outras raças e como esse contato teria ocorrido. Todo contato implicava a perda de uma pureza original. O que produzia e como se dava esse contato era um constante tema de debate. Uma raça mais ativa podia diretamente eliminar a passiva (assim se explicava o avanço dos araucanos do Pacífico - mapuches - sobre as raças que habitavam o Atlântico), mas também se colocava a possibilidade de 
misturas racial-culturais terem criado novos tipos puros e estáveis. Discutia-se, ainda, casos de impermeabilidade cultural (como entre os colonos brancos da Argentina e os indígenas da Patagônia). Esses elementos dissonantes implicavam aculturação. Para Gräbner (I940: I86), toda "atual unidade cultural está composta por vários complexos originariamente distintos”, e por isso, a fim de analisá-las, considerava adequado utilizar o conceito de aculturação, de Holmes, ou o de áreas de aculturação, de Ehrenreich, este último para as áreas de mútua aculturação (Gräbner, I940: I87). Na concepção de Gräbner, que em parte apoiava o poligenismo da humanidade, esta foi rapidamente se degradando desde sua origem prístina, e o último momento de degradação foi o contato de grandes porções da humanidade dispersas sobre o planeta com o europeu.

Outro expoente da EHC na Argentina, Fernando Márquez Miranda, estabelecia uma hierarquia a respeito e observava que esse fenômeno produzia-se especialmente quando "povos de cultura superior tomam contato com seus vizinhos menos cultos". Assim, "todos os grupos etnográficos diferentes que compõem o noroeste argentino, por exemplo - omaguacas, diaguitas, chaco-santiagueños - oferecem o claro espetáculo de empréstimos culturais, tomados da cultura incásica" (Márquez Miranda, I940: XLV). O mesmo valeria para os araucanos,

a aquisição do cavalo, que modificou profundamente todo o conjunto de seus usos e costumes (até mesmo levá-los a abandonar suas armas tradicionais, o arco e a flecha, para substituí-las pela bola de jogar e as boleadoras), ajudou-lhes a intensificar suas migrações sobre as planícies ocidentais da Pampa e da província de Buenos Aires, araucanizando a Pampa e a Patagônia, até chegar a formar aculturações tão firmes e tão intricadas que o etnógrafo não consegue chegar a desatar. Para piorar, a predicação evangelizadora, em épocas relativamente modernas, ao empregar, pela boca dos missionários - particularmente jesuítas - a língua quichua ou o guarani, ou ainda o próprio araucano, para o logro dessa penetração pacífica, reafirmou e robusteceu as primitivas aculturações com uma ratificação linguística, toponímica e, por via da linguagem, etnográfica, cujo verdadeiro e legítimo alcance não podemos, em todos os casos, hoje discriminar (Márquez Miranda, 1940: XLVII).

O Bórmida que está criando a Etnologia Tautegórica fará outra interpretação do contato e afirmará que o indígena absorve práticas e bens ocidentais, mas os ressignifica para sua própria cultura. Não se desfaz da sua cultura, mas traz a outra - a do colonizador - para si mesmo. Então, o que parece as similação e perda da cultura nativa é, na verdade, uma assimilação de bens estranhos à cultura indígena:

Ao falar da influência da civilização ocidental em um relato mítico, falamos, principalmente, do que faz à sua "conceituação" e não tanto dos traços fáticos que dessa civilização possam proceder. Com efeito, a narração pode conservar toda sua estrutura interna originária, ou grande parte dela, mesmo quando 
apareçam na sua ação elementos ergológicos ou personagens de comprovada origem ocidental. Assim, entre os Tehuelches existem numerosos mitos nos quais aparece o cavalo, o gado e, inclusive, as armas de fogo, sem que cheguem a perder estrutura própria da consciência mítica que os regem (Bórmida, 19691970b: 58).

A função desse mito pode mudar mantendo sua estrutura, mas perdendo sua qualidade de verdadeiro, condição fundamental do mito. Pode ocorrer ainda que

muitos dos traços "descidos" da cultura urbana para a cultura folclórica, embora mantenham uma identidade formal, sofrem um processo de reinterpretação e adquirem um novo sentido que não é mais o da concepção racional do mundo, na qual esses traços surgiram, mas outro que lhe brindam as estruturas da consciência mítica. [Por exemplo,] na medicina folclórica podem ser utilizados remédios ou produtos químicos da farmacopeia científica, mas um detalhado exame do seu uso nos revela que estão integrados em outro contexto técnico que não é da medicina ou da veterinária [...]; é assim que o produto agirá não só com base nas suas propriedades "naturais", isto é, ao efeito "real" que poderá exercer sobre a fisiologia do doente, mas também com base em um determinado "poder" (Bórmida, 1969-1970a: 49).

Vemos aqui claramente que o conceito de degeneração tal qual formulado por Gräbner desapareceu, e que esse processo não é exatamente aculturação, tampouco impermeabilidade cultural. Os valores e bens do homem branco são tomados pelo bárbaro. Mas este possui a capacidade de assimilá-los ao seu próprio mundo, de tirar-lhes sua "racionalidade" e torná-los míticos. Como no famoso romance de Juan Rulfo, do qual retirei a epígrafe deste artigo, subir não é descer, ir não é vir, porque o que é visto e os passos com os quais se atravessa são diferentes em um sentido ou no outro. A perspectiva é diferente. Desse ponto de vista, não existe impermeabilidade cultural, nem aculturação em um sentido estrito. Os bárbaros, ou pelo menos alguns deles, não escolherão nem a resignação (se aculturar), nem a resistência (lutar por seus direitos no jogo da política moderna). Uma terceira opção seria a assimilação, mas esta muda de perspectiva dependendo de quem olha para ela. Para o ocidental (o etnólogo inclusive), será, por exemplo - e aqui utilizo um caso que o próprio Bórmida apresenta -, o fato de que os Pilagá da província do norte de Formosa se converteram ao protestantismo. Mas, para os Pilagá, o deus cristão foi incorporado em Asién, a deidade nativa (Bórmida, I969-I970b: 58). Estritamente falando, esse fenômeno não é nem aculturação, nem resistência; é uma forma de assimilar o outro, o invasor, o estrangeiro. Assim, o que é visto como passivo não deixa de agir.

Vejo nesse raciocínio de Bórmida - lembrando que os autores não tinham conhecimento mútuo - algo semelhante ao que posteriormente Viveiros de Castro chamará de "perspectivismo ameríndio": o fato de que "numerosos 
povos do Novo Mundo (verdadeiramente todos) compartem uma concepção segundo a qual o mundo está composto por uma multiplicidade de pontos de vista: todos os existentes são centros de intencionalidade, que apreendem os outros existentes de acordo com suas perspectivas, características e capacidades" (Viveiros de Castro, 2010: 33). Então, "a inferioridade do corpo social está integramente constituída pela captura de recursos simbólicos - nomes e almas, pessoas e troféus, palavras e memórias - do exterior (Viveiros de Castro, 20I0: 145). Tal qual dizia Roy Wagner enquanto fazia trabalho de campo na Nova Guiné: "eles não me entendiam de forma diferente da que eu não os entendia" (Wagner, I98I: 20).

\section{CONSCIÊNCIA MÍTICA E RAZÃo}

Tanto Imbelloni quanto Bórmida consideravam que existem duas formas de abordar a temporalidade na antropologia: uma era a cronologia absoluta, que é obtida por análises estratigráficas, ou carbono I4, a outra era a cronologia morfológica, e implica que um grupo humano que vive simultaneamente a nós, os seres modernos, pode estar morfologicamente, em termos raciais e/ ou culturais, no passado da humanidade. A antiguidade e pureza de um tipo físico humano, um objeto ou uma prática (como um mito ou um ritual) se estabelece a partir da análise da sua forma e estilo. Por isso o elemento central é a morfologia das coisas.

Bórmida continua com essa ideia em princípio e afirmará que "todo o mundo etnográfico se encontra submergido na pré-história, pois permanece sob o signo da consciência mítica [...], e é a tomada de consciência desse afastamento que permite recortar na humanidade o objeto próprio da etnologia e jus tificar, desse modo, a autonomia e a originalidade dessa ciência [...]. Bárbaros: gente que não entendemos" (Bórmida, I969-I970a: 35). Contudo, se a distância entre o bárbaro e o civilizado é tão grande, é possível uma etnologia? É possível ter um método para entender o outro? Ocorre que Bórmida dirá que, na verdade, a distância não é tão radical. Primeiro, porque, como já vimos, mesmo no ocidental existe uma metafísica, ou seja, um mito exemplar; e "a raiz última de qualquer comportamento ou crença do homem ocidental resolve-se em um ato de fé ou em uma afirmação voluntarista baseada em supostos racionalmente indemonstráveis" (Bórmida, I969-I970a: 33). Por isso, a barbárie "não está limitada a determinados povos nem a certa época da História, nem a algumas classes sociais, mas pode estar presente em todos e cada um dos homens. A consciência mítica, que constitui seu fundamento essencial, é, então, um patrimônio potencial comum a toda a humanidade" (Bórmida, I969-I970a: 38).

Nesta altura, o leitor pensará que poderíamos assimilar os postulados de Bórmida aos de Lucien Lévi-Bruhl (I857-1939). Imbelloni afirmava que a abordagem de Lévi-Bruhl era falaciosa porque estava baseada "em uma incor- 
reta nomenclatura que permitia permutar as concepções de lógica, raciocínio, conduta, experiência e impulso mágico-religioso" (Imbelloni, I950: 220). De fato, o que foi exposto acima é muito semelhante ao último Lévi-Bruhl, o dos Carnets, nos quais afirma que não haveria uma mentalidade própria dos primitivos, mas uma parte da mentalidade humana em geral - relacionada com o afetivo, com a impressão produzida pelo insólito e o com temor do desconhecido - que poderia ser separada do resto, descrita e analisada; e o método mais simples seria fazer isso a partir dos povos primitivos (Cazeneuve, 1967: 43).

Para Bórmida, entretanto, não se trata apenas de uma postura de cordialidade com o bárbaro sem um referente empírico, pois, como advertiu em seminário ditado por ele, La conciencia mítica en la cultura media urbana, "podemos comprovar a existência de inumeráveis práticas 'supersticiosas' em pessoas de educação secundária e universitária. Nelas pudemos encontrar quase todas as estruturas mais compreensivas da consciência mítica (potência, espaço e tempo qualificados, conceito social da natureza etc.)" (Bórmida, I969-I970a: 38). Isto é o que permite a compreensão do um e do outro.

\section{PALAVRAS FINAIS}

Neste artigo quis fazer uma comparação entre um autor ítalo-argentino (ou uma esquecida linha de trabalho) com as análises mais contemporâneas de Tim Ingold e Viveiros de Castro. Tentei encontrar semelhanças, mais do que maiores diferenças; por isso não tomei como objeto o racismo de Bórmida, sua reificação da cultura ou sua dicotomização entre civilizados e bárbaros, questões estas que nada teriam a ver com os autores que são alvos da comparação. Ao contrário, enfocamos um Bórmida que desconfia da redução da vida a aspectos políticos ou econômicos, que assume que também não é possível reduzir a análise de um povo à sua estrutura, mas que devemos prestar atenção aos aspectos emotivos e experimentais, e que, sobretudo, devemos considerar ao máximo até que ponto o que os nativos afirmam é verdadeiro, real e funciona como o que é dado. Por essas razões acredito que a análise de Bórmida tem muito a ver com a dos outros dois autores.

O potencial de Bórmida e de muitos etnólogos, ao prestarem muita atenção às diferenças, é o de ser um bom antídoto para as posições assimilacionistas; porém, acontece que, muitas vezes, veem claramente em outras sociedades aquilo que não querem ver na sua própria. Assim, se para Bórmida podemos estabelecer uma diferença quase radical entre o pensamento mítico (encontrado principalmente no bárbaro) e o pensamento racional (encontrado principalmente no europeu), o interessante de abordagens como a de Ingold é que a razão e o sensível estariam distribuídos igualmente em diferentes humanidades. A razão e a emoção estariam presentes tanto no caçador quanto no cientista, mesmo que em magnitudes e momentos diferentes. Isso faz com que 
o mundo "primitivo" não seja um reservatório, como em Bórmida, mas um tipo de mundo que, utilizando a diplomacia apropriada, pode acompanhar por um longo tempo o caminho do cientista, para quem, em certas circunstâncias, até o conhecimento do caçador pode ser um ensinamento. Assim, o senso comum não seria um conhecimento pré-científico, mas, ao contrário, a própria ciência teria muito de senso comum; ambos, o caçador e o cientista, estão no mundo e têm certo "êxito" habitando-o, consequentemente não podem ser tão diferentes. Tal posição abriria uma nova possibilidade de diálogo.

Como já disse, se partimos da posição de Bórmida que separa o pensamento ocidental (racional) do pensamento bárbaro (emocional), podemos facilmente acusá-lo de racista; e acredito que realmente ele era. A complexidade está em que esse fato, que devemos criticar, não retira do seu trabalho, observando-o de outro ponto de vista, aspectos que ainda hoje nos permitem pensar no problema da alteridade. Até que ponto devemos defender a razão? Não seria ela, em última análise, uma criação do ocidente para, justamente, dividir aqueles que a têm e aqueles que não? Devemos nos esforçar em procurar racionalidade em contingentes humanos que nunca a reivindicaram? Um dos giros interpretativos mais interessantes que, acredito, Viveiros de Castro deu à obra de Lévi-Bruhl, foi entender que "a ausência de conceito racional pode ser vista positivamente como signo da desalienação existencial dos povos em questão, manifestação de um estado de não-separabilidade do conhecer e o agir, do pensar e do sentir" (Viveiros de Castro, 2010: 62). Assim poderíamos também reler a Etnologia Tautegórica de Marcelo Bórmida.

Contudo, por que encontramos similitudes nesses três autores? Não vou dar uma solução a respeito, mas tendemos a pensar que esse tipo de semelhança ocorre porque todos eles, direta ou indiretamente, beberam de uma ou várias ideias originais, geradas por alguém em algum lugar e época, referentes à fenomenologia ou à etnologia. Mas e se as semelhanças não estivessem relacionadas à circulação das ideias, e sim ao fato de que esses autores, em lugares e tempos diferentes, encontraram situações empíricas semelhantes nos seus diferentes trabalhos de campo? Realmente os três, por exemplo, trabalharam em áreas onde o xamanismo ocupa um lugar central na configuração das cosmologias nativas. Não quero defender nem uma, nem outra tese, mas é verdade que a última posição nos traria de volta uma empresa que autores como Ingold tentam promover: a empresa de voltar ao campo da ciência empírica e contrastável, sem que isso implique se subordinar aos parâmetros das ciências naturais. ${ }^{5}$ 
Rolando Silla é doutor em Antropologia Social pelo Programa de Pós-Graduação em Antropologia Social da Universidade Federal do Rio de Janeiro (PPGAS-UFRJ), pesquisador do Consejo Nacional de Investigaciones Científicas y Técnicas/ Instituto de Altos Estudios Sociales de la Universidad Nacional de San Martín (CONICET/IDAES-UNSAM) e professor de Antropologia Social e Cultural na mesma universidade. Atualmente suas pesquisas enfocam as concepções e distinções entre o humano, o natural e o sobrenatural entre camponeses de Neuquén e a antropologia argentina, especialmente a Escola Histórico-Cultural e a fenomenologia. Organizou, para a revista Papeles de Trabajo, o dossiê Materialidad y agencia: un debate con la obra de Tim Ingold (2013), e nele publicou "Tim Ingold, neomaterialismo y pensamiento pos-relacional en antropologia". 


\section{NOTAS}

* Uma primeira versão deste trabalho foi apresentada no XI Congresso Argentino de Antropologia Social, realizado em Rosario, Argentina, em 20I4. Sou grato a Gastón Gil, Rosana Guber e Otávio Velho pelos comentários.

I Neste artigo analisarei apenas esta primeira abordagem, deixando os futuros desenvolvimentos de Marcelo Bórmida para outra oportunidade.

2 Imbelloni também já tinha criticado o sociologismo na sua versão francesa (Imbelloni, I945: 34).

3 A rigor, para Bórmida, também não existe uma diferença radical entre a magia e a ciência, mas as razões são justamente as inversas: o cientista, como veremos adiante, também sustenta uma metafísica, ainda que ele a negue. Esse é outro dos pontos que, acredito, leva Bórmida, apesar dele mesmo, ao debate sobre a possibilidade de conceber múltiplas naturezas, assim como múltiplas modernidades.

4 Ingold também acrescenta que na ontologia medieval, os dragões existiam da mesma maneira que existia o medo, ou seja, não como um elemento do mundo real, mas como um fenômeno da experiência (ver Ingold, 2012: I9).

5 Devo esta última observação a Otávio Velho.

\section{REFERÊNCIAS BIBLIOGRÁFICAS}

Bartolomé, Leopoldo. (I982). Panorama y perspectivas de la antropología social en la Argentina. Desarrollo Económico, 22/87, p. 409-420.

Bórmida, Marcelo. (I969-I970a). Mito y cultura. Runa. Archivos para la Ciencia del Hombre. XII, Parte I-2, p. 9-52.

Bórmida, Marcelo. (1969-I970b). Problemas de heurística mitográfica. Las fuentes míticas a nivel etnográfico. Runa. Archivos para la Ciencia del Hombre. XII, Parte I-2, p. 53-65.

Bórmida, Marcelo. (1953-54). Los antiguos patagones. Estudio de craneología. Runa. Archivos para la Ciencia del Hombre. VI, Parte I-2, p. 5-96.

Bórmida, Marcelo. (I95I). Algunas luces sobre la penumbrosa Isla de Pascua antes de I722. Runa. Archivos para la Ciencia del Hombre, IV, p. 63-75. 
Boschín, María. (I99I-I992). Historia de las investigaciones arqueológicas en Pampa y Patagonia. Runa. Archivos para la Ciencia del Hombre, XX, p. III-I44.

Cazeneuve, Jean. (1967). La mentalidad arcaica. Buenos Aires: Siglo XX.

Durkheim, Émile \& Marcel Mauss. (I97I [1903]). De ciertas formas primitivas de clasificación. Contribución al estudio de las representaciones colectivas. In: Institución y culto. Obras II. Barcelona: Barral, p. 222-280.

Evans-Pritchard, Edward E. (1976 [1937]). Brujería, magia y oráculos entre los Azande. Barcelona: Anagrama.

Fígoli, Leonardo H. G. (I990). A ciência sob o olhar etnográfico. Estudo da antropologia argentina. Tese de doutorado/ Universidade de Brasília.

Frazer, James G. (I996 [I922]). La rama dorada. México: Fondo de Cultura Económica.

Garbulski, Edgardo O. (1992). La antropología social en la Argentina. Runa. Archivos para la Ciencia del Hombre, XX, p. 4-25.

Gingrich, Andre (2005). Prelude and overture: from early travelogues to German Enlightenment. In: Vários Autores. One discipline, four ways: British, German, French, and American Anthropology. Chicago: University of Chicago Press, p. I 22-I 48 .

González, Alberto Rex. (I992). A cuatro décadas del comienzo de una etapa. Apuntes marginales para la historia de la antropología argentina. Runa. Archivos para la Ciencia del Hombre, XX, p. 26-32.

Gräbner, Fritz. (I940 [I9II]). Metodología etnológica. La Plata: Universidad Nacional de La Plata.

Guber, Rosana \& Sergio Visakovsky. (2006). The birth of "ciencias antropológicas" at the University of Buenos Aires, I955-I965. In: Darnel, Regna \& Gleach, Frederic (orgs.). Histories of Anthopology Annual, 2. Nebraska: University of Nebraska Press.

Guber, Rosana \& Sergio Visakovsky. (I999). Controversias filiales: la imposibilidad genealógica de la antropología social de Buenos Aires. Relaciones de la Sociedad Argentina de Antropología, XXII-XXIII, p. 25-53. 
Imbelloni, José (1945). La linfa de la scienza nuova y sus manantiales. Buenos Aires: Academia Argentina de Letras. Ingold, Tim. (2012). Caminhando com dragões: em direção ao lado selvagem. In: Steil, Carlos Alberto \& Carvalho, Isabel Cristina de Moura (orgs.). Cultura, percepção e ambiente. Diálogos com Tim Ingold. São Paulo: Terceiro Nome, p. I5-29. Ingold, Tim. (2002). The perception of the environment. Essays in livelihood, dwelling and skill. Londres: Routledge.

Ingold, Tim. (I996). Key debates in anthropology. Londres: Routledge.

Ingold, Tim. (1993). The art of translation in a continuous world. In: Pálsson, Gísli (org.). Beyond boundaries: understanding, translation and anthropological discourse. Oxford: Berg Publishers, p. 210-23I.

Leach, Edmund. (I995 [I954]). Sistemas políticos da Alta Birmânia. São Paulo: Edusp.

Malinowski, Bronislaw. (I986 [1922]). Los argonautas del Pacífico occidental. Barcelona: Planeta-Agostini.

Márquez Miranda, Fernando. (I940). Prólogo. In: Gräbner, Fritz. Metodología etnológica. La Plata: Universidad Nacional de La Plata.

Menghín, Oswald F. A. (I953-I954). El desarrollo de las culturas, a propósito de una obra recentísima. Runa. Archivos para la Ciencia del Hombre, VI, Parte I-2, p. 200-2IO.

Reynoso, Carlos. (2006). Antropología de la música. De los géneros tribales a la globalización. Buenos Aires: SB.

Vernant, Jean-Pierre. (I99I). Mito y religión en la Grecia antigua. Barcelona: Ariel.

Viveiros de Castro, Eduardo. (2010). Metafísicas caníbales. Líneas de antropología posestructural. Madri: Katz.

Wagner, Roy. (I98I). The invention of culture. Chicago: The University of Chicago Press 
ETNOLOGIA E FENOMENOLOGIA. UM COMENTÁRIO DAS OBRAS DE MARCELO BÓRMIDA, TIM INGOLD E EDUARDO VIVEIROS DE CASTRO

\section{Resumo}

Neste artigo, centrado nas minhas investigações a respeito do desenvolvimento da Antropologia na Argentina, analiso dois dos primeiros trabalhos de Marcelo Bórmida abertamente etnológicos e fenomenológicos, com o objetivo de explorar certas relações a partir da etnologia, com a obra de Viveiros de Castro, e da fenomenologia, com as posições de Ingold. Para tanto serei obrigado a ampliar o campo de análise para outros antropólogos argentinos vinculados a Bórmida, além de antropólogos e cientistas sociais do campo acadêmico anglo-saxão e francês. O sentido da comparação é encontrar similitudes e diferenças, mas também ver até que ponto abordagens de autores como Viveiros de Castro ou Ingold se ancoram, assim como a de Bórmida, em "resíduos de não-tradições".

\section{ETHNOLOGY AND PHENOMENOLOGY. COMMENTS ON THE WORKS OF MARCELO BÓRMIDA, TIM INGOLD, AND EDUARDO VIVEIROS DE CASTRO} ethnology with Viveiros de Castro's work and from that of phenomenology with Tim Ingold's propositions. With this aim in view, the scope will be broadened so as to include other Argentinean anthropologists who are linked to Bórmida, as well as anthropologists and social scientists from the Anglo-Saxon and French academic field. The comparison seeks to find similarities and differences, but also to show the extent to which the perspectives of Viveiros de Castro or Ingold, as well as Bórmida's, are based on "residues of non-traditions".
Palavras-chave

Etnologia e

fenomenologia;

Mito;

Marcelo Bórmida;

Tim Ingold;

Eduardo Viveiros de Castro.
Keywords

Ethnology and phenomenology;

Myth;

Marcelo Bórmida;

Tim Ingold;

Eduardo Viveiros de Castro. 